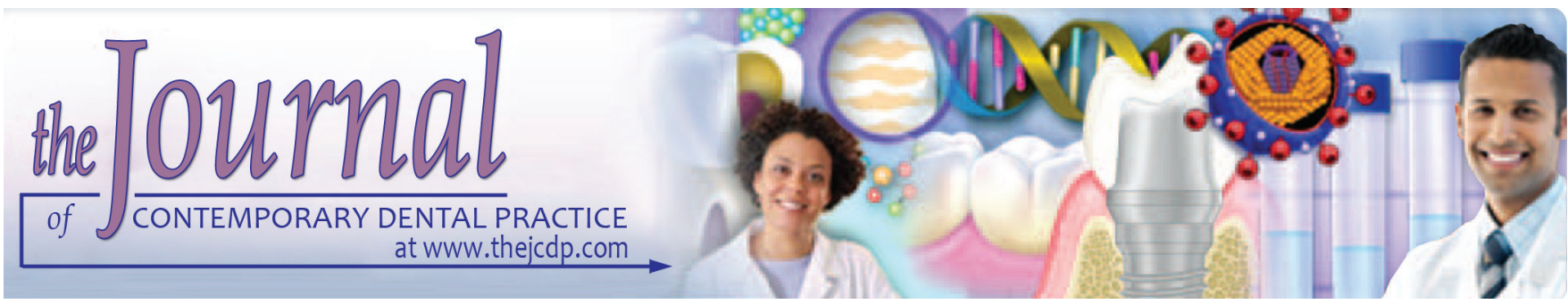

\title{
Evaluation of Flexural Strength of Polymethyl Methacrylate modified with Silver Colloidal Nanoparticles subjected to Two Different Curing Cycles: An in vitro Study
}

${ }^{1}$ Ranganath L Munikamaiah, ${ }^{2}$ Saket K Jain, ${ }^{3}$ Kapil S Pal, ${ }^{4}$ Ajay Gaikwad

\begin{abstract}
Aim: Silver colloidal nanoparticles have been incorporated into acrylic resins to induce antimicrobial properties. However, as additives, they can influence the mechanical properties of the final product. Mechanical properties are also dependent on different curing cycles. The aim of this study was to evaluate flexural strength of a denture base resin incorporated with different concentrations of silver colloidal nanoparticles subjected to two different curing cycles.
\end{abstract}

Materials and methods: Lucitone 199 denture base resin was used into which silver colloidal nanoparticles were incorporated at 0.5 and $5 \%$ by polymer mass. Specimens devoid of nanoparticles were used as controls. A total of 60 specimens were fabricated and divided into two groups. Each group was divided into three subgroups consisting of 10 specimens each. The specimens were fabricated according to American Dental Association (ADA) specification No. 12 and tested for flexural strength using universal testing machine.

Results: Silver colloidal nanoparticle incorporation at $0.5 \%$ concentration increased the mean flexural strength in both curing cycles by 7.5 and $4.4 \%$, respectively, when compared with the control group.

Conclusion: The study suggested that the mean flexural strength value of $0.5 \%$ silver colloidal nanoparticles in denture base resin was above the value of the control group both in short and long curing cycles, which makes it clinically suitable as a denture base material. However, at $5 \%$ concentration, the statistically significant amount of decrease in flexural strength compared with the value of control group both in short and long curing cycles gives it a questionable prognosis.

\footnotetext{
${ }^{1-4}$ Department of Prosthodontics, RKDF Dental College and Research Centre, Bhopal, Madhya Pradesh, India
}

Corresponding Author: Ranganath L Munikamaiah Department of Prosthodontics, RKDF Dental College and Research Centre, Bhopal, Madhya Pradesh, India, Phone: +919845056441, e-mail: dentique@ymail.com
Clinical significance: The specimens incorporated with the antimicrobial agent $0.5 \%$ silver colloidal nanoparticles and processed by long curing cycles showed significant increase in its flexural strength compared with the control group, which makes it clinically suitable as a denture base material.

Keywords: Acrylic resin, Antimicrobial agents, Silver nanoparticles.

How to cite this article: Munikamaiah RL, Jain SK, Pal KS, Gaikwad A. Evaluation of Flexural Strength of Polymethyl Methacrylate modified with Silver Colloidal Nanoparticles subjected to Two Different Curing Cycles: An in vitro Study. J Contemp Dent Pract 2018;19(3):262-268.

Source of support: Nil

Conflict of interest: None

\section{INTRODUCTION}

About 50 to $70 \%$ of complete denture wearers present a pathogenic state known as denture stomatitis. ${ }^{1}$ This pathology is an inflammatory process characterized by homogeneous erythema or red focal areas, especially in the palatal mucosa and usually associated with Candida species, particularly Candida albicans. ${ }^{2}$ Stomatitis represents a challenge for the dental field, and methods for the prevention of denture stomatitis, such as the incorporation of antimicrobial agents into polymers used as denture base and as tissue conditioners, have been developed. In contrast, silver (Ag) has been widely used in medical and life-care polymers and exhibits antimicrobial action. Silver ions $(\mathrm{Ag}+)$ bind to electron donor groups in biological molecules containing sulfur or nitrogen, resulting in defects in the bacterial cell membrane and leading to loss of their cell contents and to the death of bacteria. ${ }^{3}$

The use of silver nanoparticles as antimicrobial agents has received a great deal of attention. Silver nanoparticles are incorporated into polymethyl methacrylate (PMMA) 


\begin{tabular}{lll}
\hline \multicolumn{3}{c}{ Table 1: Materials used in the study } \\
\hline Trade name & Material & Manufacturer \\
\hline Lucitone 199 & PMMA denture base resin & Dentsply \\
Silver colloidal & Ag nanoparticles, colloidal & Reinste \\
nanoparticle & solution in water & Nanoventures \\
& Average particle size: & \\
& 10-20 nm & \\
\hline
\end{tabular}

denture resin to attain an effective antimicrobial material to control common infections of oral mucosal tissues in complete denture wearers. ${ }^{4}$

Acrylic resins are the most widely used materials for the fabrication of denture bases. This is due to their acceptable esthetics, ease of handling, good thermal conductivity, low permeability to oral fluids, and color stability. ${ }^{5}$ The desirable qualities of PMMA are offset by certain drawbacks, significant among them are its reduced strength and stiffness. Fracture occurs as a result of fatigue when PMMA cannot withstand intraoral forces and extraoral impact forces because of insufficient transverse, impact, flexural, compressive, and fatigue strengths. Various researchers have proposed modalities for strengthening the resin like embedding of solid metal forms in the resin and reinforcing of acrylic resin with various fibers. ${ }^{6}$

Although the literature reports various studies related to silver nanocomposites with antimicrobial application in the medical field, ${ }^{7}$ very few studies about addition of silver particles to denture base resins have been published. The aim of this in vitro study was to evaluate flexural strength of a denture base resin containing different concentrations of silver colloidal nanoparticles when subjected to two different curing cycles.

\section{MATERIALS AND METHODS}

The following materials were used for conducting the study (Table 1).

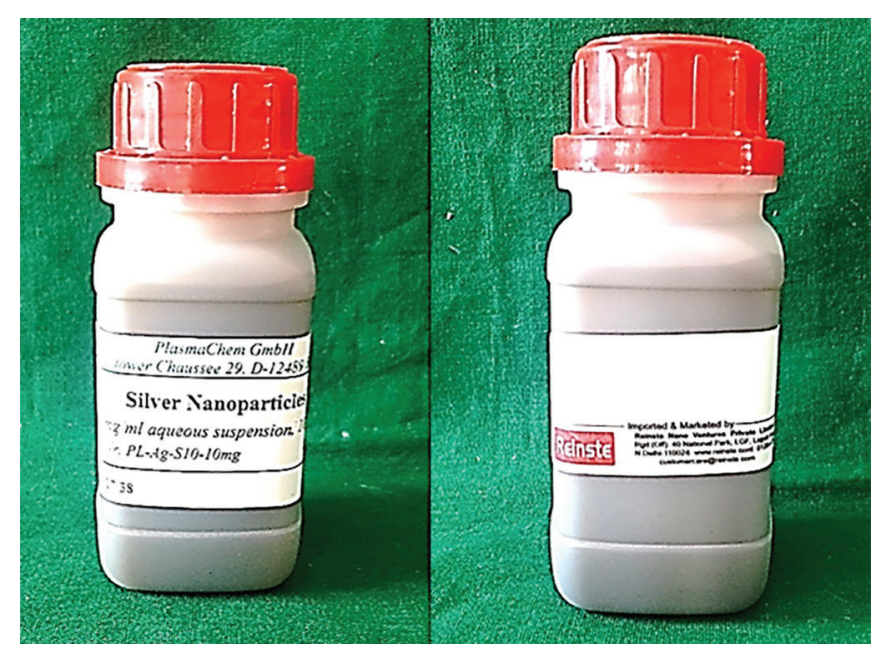

Fig. 1: Silver colloidal nanoparticles

\section{Preparation of PMMA/Ag Nanocomposites}

The aqueous colloidal dispersion containing silver nanoparticles (Fig. 1) was added to the monomer of the acrylic resin at 0.5 and $5 \%$, based on the polymer mass. A total of $50 \mathrm{~mL}$ solution of monomer was prepared for each concentration. The polymer and the modified monomer were mixed in a ceramic mixing jar according to the manufacturer's recommended polymer and monomer ratio.

\section{Methodology for the Preparation of Test Specimens for evaluating Flexural Strength}

Acrylic resin specimens measuring $65 \mathrm{~mm} \times 10 \mathrm{~mm} \times$ $3 \mathrm{~mm}$ were fabricated according to ADA Specification No. $12^{8,9}$ by the following procedure:

A stainless steel die measuring $65 \mathrm{~mm} \times 10 \mathrm{~mm} \times$ $3 \mathrm{~mm}$ was fabricated (Fig. 2). The stainless steel die was invested with dental stone (Caldent dental stone, Kalabhai Karson Pvt. Ltd.) in regular brass flasks using conventional technique (Fig. 3). After the dental stone had set, separating medium was applied and the second pour was done. The flask was closed and tightened in a clamp.

After the second pour of dental stone had set, the flasks were separated and thoroughly flushed with water and air pressure was used to separate stainless steel die from dental stone (Fig. 4). The flask was cleaned with soap water and dried in open air. A thin, single uniform layer of separating medium (tin foil substitute) was applied to dental stone on both the parts of the flask.

Silver colloidal nanoparticles were incorporated into acrylic resin (Lucitone 199, Dentsply) at concentrations of 0.5 and $5 \%$ by volume. The polymer powder was mixed with the monomer according to the manufacturer's instructions. The resin was left in the closed mixing jar until it reached the dough stage, and then, the mix was

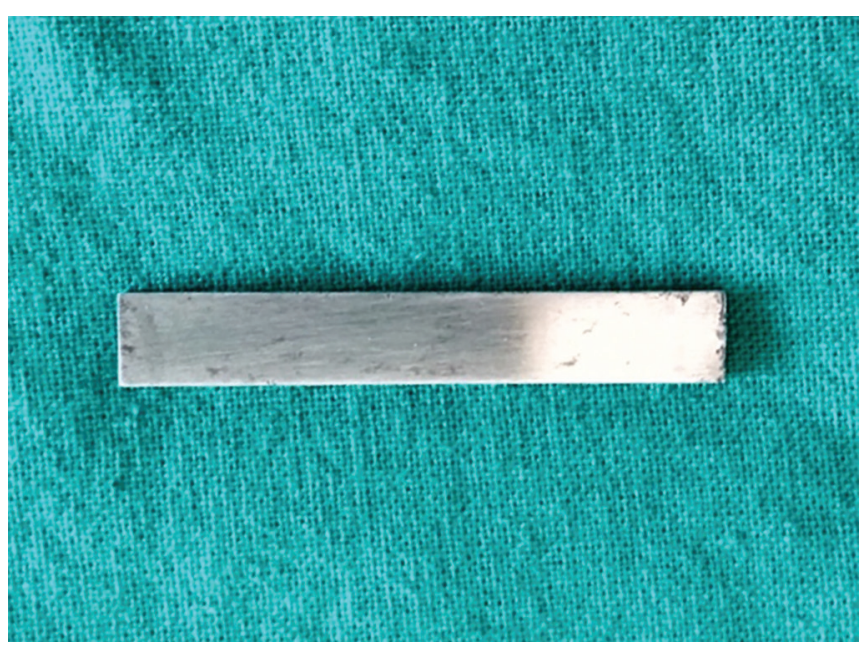

Fig. 2: Stainless steel die for flexural strength test 


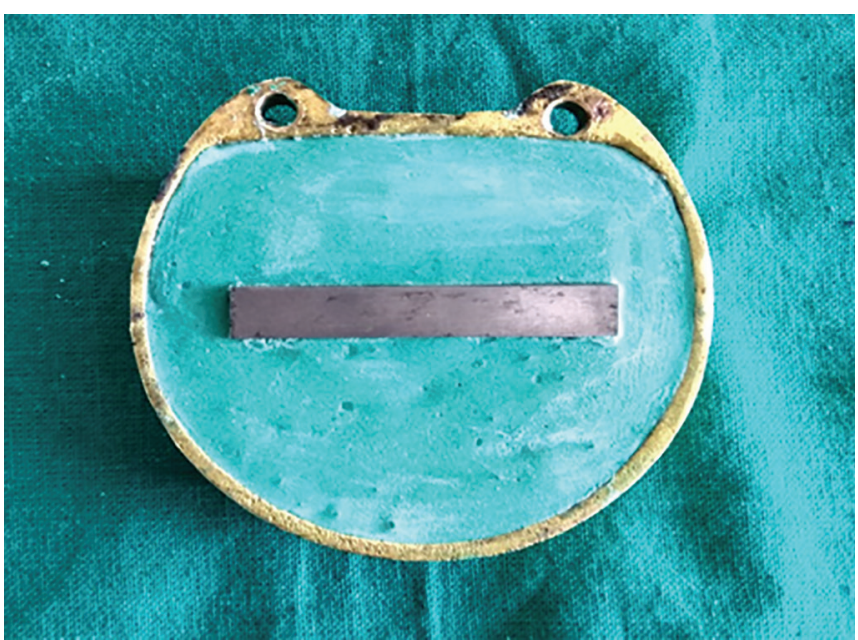

Fig. 3: Steel die in dental stone

kneaded thoroughly to homogeneous dough. The dough was packed into the flask with a thin, wet, and wiped cellophane sheet placed over it. The flask lid was closed properly and placed under 1,500 psi pressure in a bench press to compress the material into the mold. Trial closure was carried out till no flash was present. After the final closure, the flasks were bench cured for 30 minutes at room temperature.

All the specimens were polymerized using a standard processing cycle. The standard processing cycle chosen was the ADA-specified short and long curing cycles. The clamped flasks were immersed in an acrylizer containing water at room temperature. The processing was carried out at $74^{\circ} \mathrm{C}$ for 90 minutes and at $100^{\circ} \mathrm{C}$ for 30 minutes (short curing cycle) and at $74^{\circ} \mathrm{C}$ for 8 hours (long curing cycle). After the completion of curing cycle, the acrylizer was switched off and flasks were bench cooled overnight at room temperature before deflasking. After complete cooling, the test specimens were carefully retrieved and finished (Fig. 5).

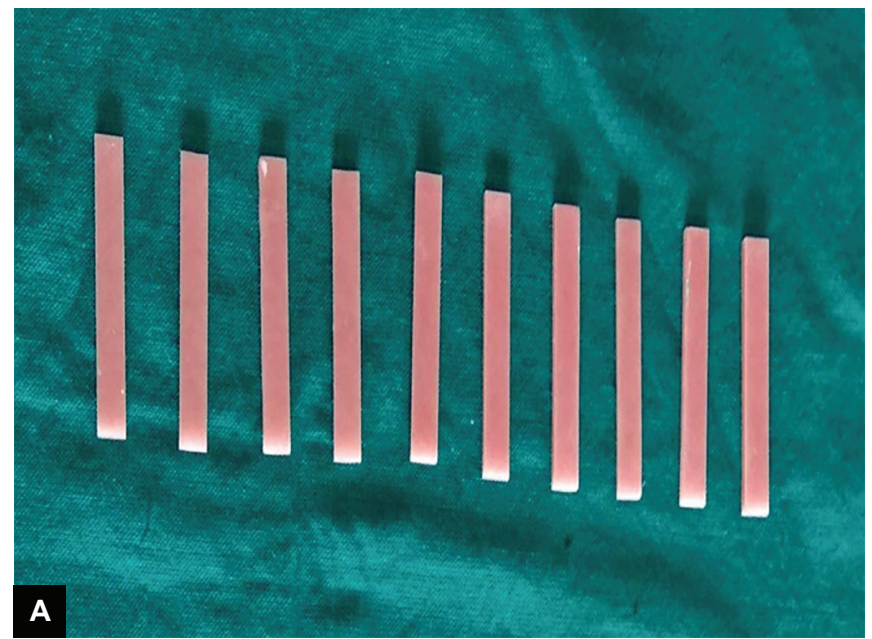

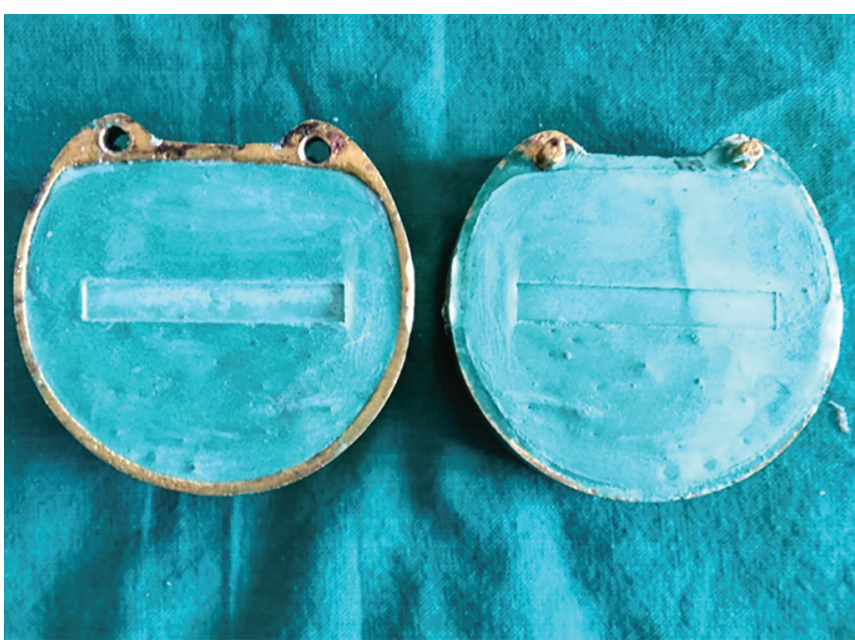

Fig. 4: Mold space after steel die removal

\section{Grouping of Specimens}

A total number of 60 specimens were fabricated. The specimens were divided into two groups, i.e., group Ishort curing cycle and group II-long curing cycle. Each group was divided into three subgroups of 10 specimens each, i.e., consisting of one subgroup of control (conventional PMMA) and two subgroups of modified PMMA.

\section{Group I: Short Curing Cycle}

- Subgroup A-control group (without silver colloidal nanoparticles)

- Subgroup B-0.5\% by volume silver colloidal nanoparticles

- Subgroup C-5\% by volume silver colloidal nanoparticles

\section{Group II: Long Curing Cycle}

- Subgroup A-control group (without silver colloidal nanoparticles)

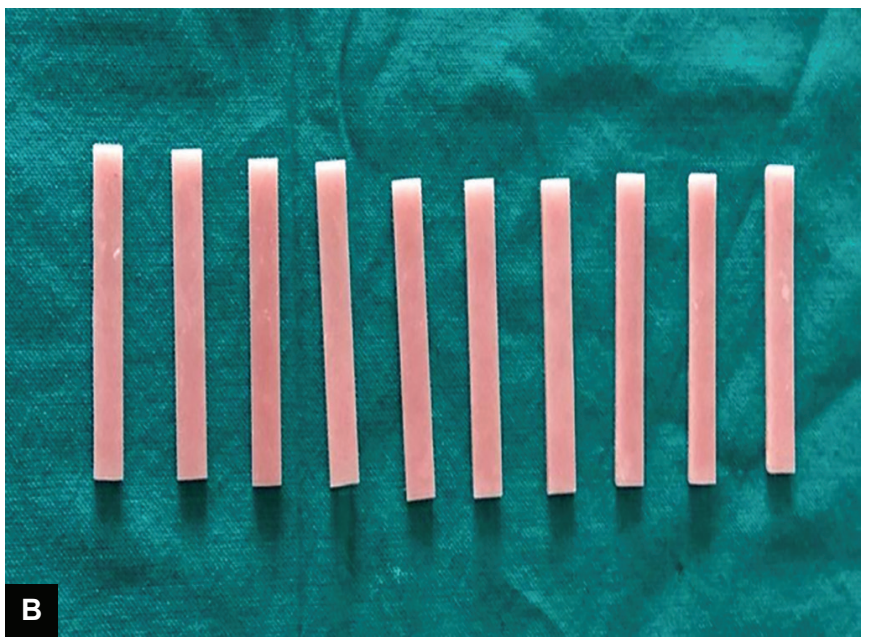

Figs 5A and B: (A) Group I (control group); and (B) group II (control group) 

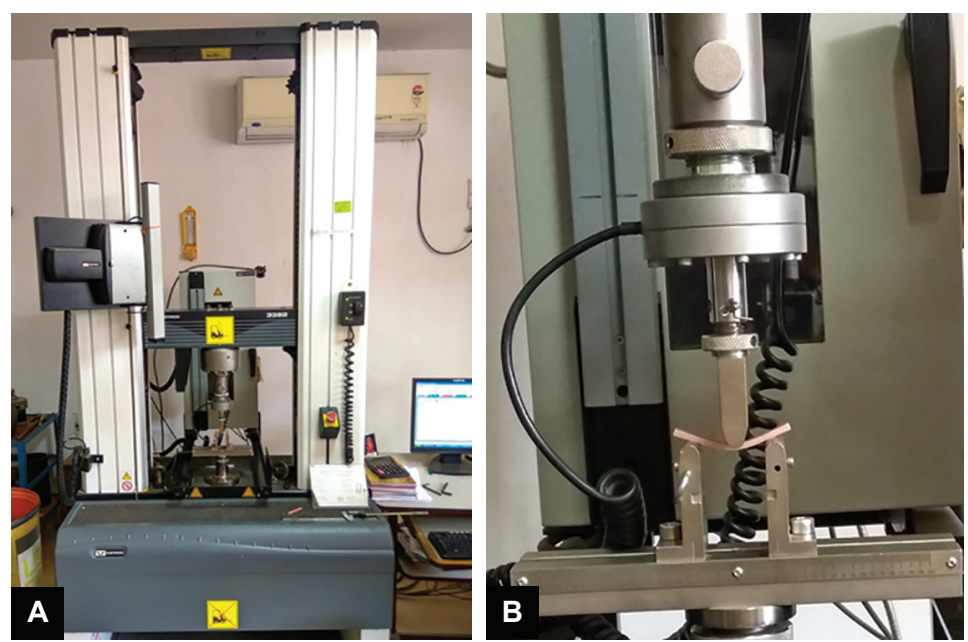

Figs 6A and B: (A) Universal testing machine and (B) testing of specimen

- Subgroup B-0.5\% by volume silver colloidal nanoparticles

- Subgroup C-5\% by volume silver colloidal nanoparticles

\section{Flexural Strength Test}

The evaluation for the detection of flexural strength was carried out in universal testing machine (Instron Corp. model no. 3382, Canton, MS, USA) (Fig. 6A) specially equipped with grips suitable for holding the test specimen set at cross-sectional area head speed of $2 \mathrm{~mm} / \mathrm{min}$ with a chart speed of $20 \mathrm{~mm} / \mathrm{min}$. A load was applied using a centrally located rod until a fracture occurred (Fig. 6B).

\section{Statistical Analysis}

Data were analyzed with Statistical Package for the Social Sciences version 19. Descriptive statistics were used to compare two different curing cycles; one-way analysis of variance test was used to compare the variance between the two different groups using single variable, $\mathrm{K}$ independent test was used to compare the different silver colloidal nanoparticle concentrations and effect of the same on flexural strength. Statistical significance was set at $p<0.05$.

\section{RESULTS}

The flexural strength of the acrylic denture base resin with silver colloidal nanoparticle incorporation at $0.5 \%$

Table 2: Descriptive statistics of all subgroups of group I for flexural strength (MPa)

\begin{tabular}{ll}
\hline Group I & Mean \pm SD \\
\hline Subgroup A & $79.07 \pm 0.89$ \\
Subgroup B & $85.05 \pm 1.13$ \\
Subgroup C & $73.4 \pm 0.81$ \\
\hline
\end{tabular}

concentration increased the mean flexural strength in both curing cycles by 7.5 and $4.4 \%$, respectively, when compared with the control group.

Table 2 summarizes the mean and standard deviation (SD) of flexural strength values of control and all tested subgroups of group I, i.e., short curing cycle, where subgroups are divided according to the silver colloidal nanoparticles concentration. Subgroup B ( $0.5 \%$ silver colloidal nanoparticles) has the highest mean flexural strength value ( $85.05 \mathrm{MPa})$ and subgroup C (5\% silver colloidal nanoparticles) has the lowest mean flexural strength value (73.4 MPa) which is $7.2 \%$ lower than the control group.

Table 3 summarizes the mean and SD of flexural strength values of control and all tested subgroups of group II, i.e., long curing cycle, where subgroups are divided according to the silver colloidal nanoparticles concentration. Subgroup B $(0.5 \%$ silver colloidal nanoparticles) has the highest mean flexural strength value ( $88.57 \mathrm{MPa})$ and subgroup C ( $5 \%$ silver colloidal nanoparticles) has the lowest mean flexural strength value $(78.34 \mathrm{MPa})$, which is $7.7 \%$ lower than the control group.

Table 4 summarizes the comparison of mean flexural strength values of all subgroups of groups I and II using $\mathrm{K}$ independent sample test. It reveals that among all the subgroups, subgroup B $(0.5 \%$ silver colloidal nanoparticles) was found highly significant at 0.000 levels, with F-score of 53.79.

Table 5 summarizes the comparison of mean flexural strength values of all subgroups of group I, i.e., short curing cycle using $\mathrm{K}$ independent sample test. It reveals

Table 3: Descriptive statistics of all subgroups of group II for flexural strength (MPa)

\begin{tabular}{ll}
\hline Group II & Mean \pm SD \\
\hline Subgroup A & $84.84 \pm 1.24$ \\
Subgroup B & $88.57 \pm 1.01$ \\
Subgroup C & $78.34 \pm 0.85$ \\
\hline
\end{tabular}


Table 4: Comparison of mean flexural strength values of all subgroups of groups I and II

\begin{tabular}{lll}
\hline Silver concentrations (\%) & F-score & $p$-value \\
\hline 0 & 178.62 & 0.084 \\
0.5 & 53.79 & $0.000^{*}$ \\
5 & 142.86 & 0.061 \\
\hline *Highly significant at significance level 5\%
\end{tabular}

*Highly significant at significance level 5\%

Table 6: Comparison of flexural strength of all subgroups of group II

\begin{tabular}{lll}
\hline Silver concentrations (\%) & F-score & $p$-value \\
\hline 0 & 378.21 & 0.132 \\
0.5 & 321.1 & $0.021^{*}$ \\
5 & 291.1 & 0.19 \\
\hline
\end{tabular}

*Significant at significance level 5\%

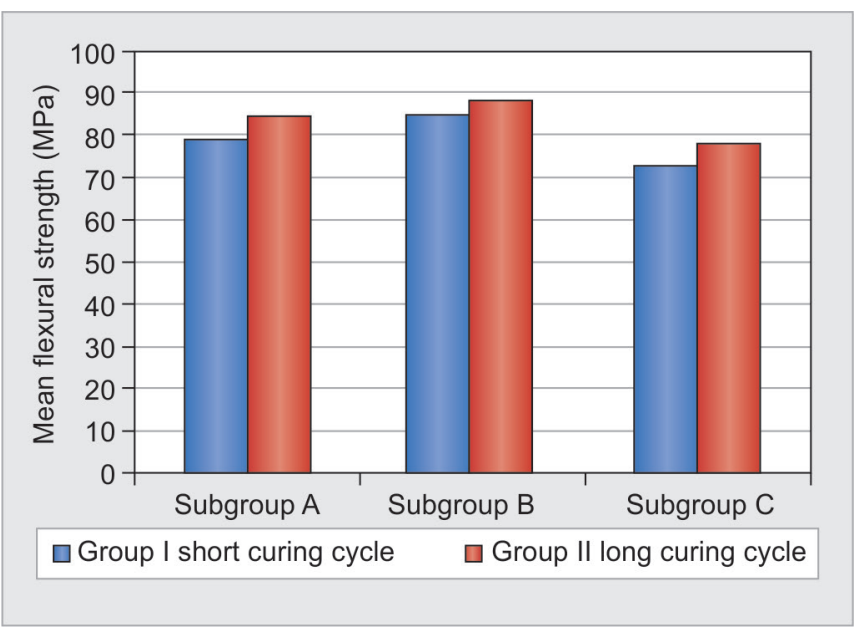

Graph 1: Comparison of mean flexural strength values among all subgroups of groups I and II

that among all the subgroups, subgroup B $(0.5 \%$ silver colloidal nanoparticles) was found highly significant at 0.023 levels, with F-score of 312.9.

Table 6 summarizes the comparison of mean flexural strength values of all subgroups of group II, i.e., long curing cycle using $\mathrm{K}$ independent sample test. It reveals that among all the subgroups, subgroup B $(0.5 \%$ silver colloidal nanoparticles) was found highly significant at 0.021 levels, with F-score of 321.1.

Graph 1 compares mean flexural strength values among all subgroups of groups I and II. The mean flexural strength value $(88.57 \mathrm{MPa})$ of subgroup B $(0.5 \%$ silver nanoparticles) of group II, i.e., long curing cycle, is significantly higher than the values of subgroup $\mathrm{A}$ (control group, $84.84 \mathrm{MPa}$ ) and subgroup C (5\% silver nanoparticles, $78.34 \mathrm{MPa}$ ) of both the groups respectively.

\section{DISCUSSION}

Complete dentures are most commonly used by geriatric patients. Patients with complete denture often neglect
Table 5: Comparison of flexural strength of all subgroups of group I

\begin{tabular}{lll}
\hline Silver concentrations (\%) & F-score & $p$-value \\
\hline 0 & 324.76 & 0.086 \\
0.5 & 312.9 & $0.023^{*}$ \\
5 & 297.76 & 0.12 \\
\hline
\end{tabular}

*Significant at significance level 5\%

their denture and oral health by improper maintenance of denture, resulting in bad oral health and denture hygiene.

Denture stomatitis is a pathogenic state present in about 50 to $80 \%$ complete denture wearers. It is an inflammatory process characterized by pinpoint erythemas, granular focal areas, especially in the palatal mucosa, usually associated with C. albicans. ${ }^{10}$

Silver nanoparticles also have a rapid and broadspectrum efficacy and sustained silver cation release in comparison to micro-sized silver powder $(\mu \mathrm{m})$, making them more effective than the latter.

Due to their small size, nanoparticles present larger surface area and appear to be more effective means of prophylaxis than micro-sized silver powder $(\mu \mathrm{m})$, which shows lower antimicrobial activity owing to its limited surface. ${ }^{5}$

Kvitek et $\mathrm{l}^{11}$ reported that the silver nanoparticles having diameter of $25 \mathrm{~nm}$ caused death of the human fibroblasts at the concentrations higher than $60 \mathrm{mg} / \mathrm{L}$. The author suggested that tested composites with concentrations up to $40 \mathrm{ppm}$ of silver nanoparticles should be safe in an oral cavity environment, but this assumption should be clearly confirmed in further investigations.

Moreover, composites with a high antifungal efficacy could have a negative influence on the physiological microflora in the oral cavity. However, the antifungal efficacy values obtained in the environment surrounding specimens with concentrations from 20 to $40 \mathrm{ppm}$ should eliminate fungi on the surface and inside of the material. ${ }^{12}$ Hence, 40 ppm of silver nanoparticles at 10 to $20 \mathrm{~nm}$ was used for the present study.

Although the literature reports various studies related to silver nanocomposites with antimicrobial applications in the medical field, very few studies concerning addition of silver nanoparticles to denture base resins have been published. A pilot study by Monteiro et a ${ }^{4}$ evaluated the antimicrobial efficacy of the PMMA/Ag nanocomposites incorporated with silver colloidal nanoparticles at 0.5 and $5 \%$ against $C$. albicans. The results showed that the nanocomposites had good antimicrobial properties against C. albicans, especially the PMMA/Ag nanocomposites containing 5\% silver colloidal nanoparticles. Casemiro et $\mathrm{al}^{13}$ reported an evaluation of a commercial acrylic resin containing a $2.5 \%$ silver and zinc zeolite compound, the results of which indicated higher antimicrobial activity but decreased flexural and impact strength. 
Meng and Latta ${ }^{14}$ conducted a study to evaluate the physical properties of four acrylic denture base resins, i.e., Lucitone 199, Fricke Hi-I, ProBase Hot, and Sledgehammer Maxipack, and results revealed that Lucitone 199 with an Izod impact strength of $5.5 \pm 1.2 \mathrm{Nm}$, a flexural strength of $99.5 \pm 4.5 \mathrm{MPa}$, and yield distance of $9.9 \pm 0.76 \mathrm{~mm}$ exhibited statistically significant results than Fricki Hi-I, ProBase Hot, and Sledgehammer Maxipack. That is why we had used Lucitone 199 (Dentsply) for this present study.

Arundati and Patil ${ }^{15}$ carried out a study to evaluate and compare the transverse and impact strength of a new high-impact denture base resin and it was compared with two most commonly available resins in the market subjected to short and long curing cycles. They found that the long curing cycle showed considerably higher values of transverse and impact strength as compared with the short curing cycle.

The present study evaluated the flexural strength of acrylic denture base resin (Lucitone 199, Dentsply) after incorporation of different concentrations of silver nanoparticles and subjected to two different curing cycles.

For evaluating flexural strength, a stainless steel die measuring $65 \mathrm{~mm} \times 10 \mathrm{~mm} \times 3 \mathrm{~mm}$ according to ADA specification No. $12^{8,9}$ was fabricated.

The present study consisted of a total of 60 specimens for evaluating flexural strength. The 60 specimens were divided into two groups (30 specimens in each), and each group was divided into subgroup A (control group, PMMA without silver nanoparticles), subgroup B (PMMA containing $0.5 \%$ silver nanoparticles.), and subgroup C (PMMA containing 5\% silver nanoparticles).

Specimens were tested for flexural strength using a universal testing machine (Instron Corp. model no. 3382, Canton, MS, USA). Load was applied on the specimen of acrylic at a cross-head speed of $2 \mathrm{~mm} / \mathrm{min}$ till the specimen fractured.

All specimens in this study were subjected to a sustained and progressively increasing force until fracture occurred. The resulting flexural strengths were recorded, statistically analyzed, and compared.

The results of the present study revealed that the flexural strength values decreased gradually with an increase in the silver nanoparticle concentration of the resin. The flexural strength of the acrylic denture base without any incorporation of silver colloidal nanoparticles (control group) showed the values $79.07 \mathrm{MPa}$ (short curing cycle) and $84.84 \mathrm{MPa}$ (long curing cycle), whereas $0.5 \%$ silver colloidal nanoparticles were above the control group value, i.e., $85.05 \mathrm{MPa}$ (short curing cycle) and 88.57 MPa (long curing cycle). However, the flexural strength of denture base resin modified with $5 \%$ silver nanoparticles was 73.4 MPa (short curing cycle) and $78.34 \mathrm{MPa}$ (long curing cycle), which was well below the baseline value.

It was revealed from the results of our study that the denture base resin with incorporation of $0.5 \%$ silver colloidal nanoparticle gave highest flexural strength in both the processing cycles, i.e., short and long curing cycle.

The silver colloidal nanoparticle incorporation into denture base acrylic resin at a concentration of $0.5 \%$ showed increase in the mean flexural strength value by $7.5 \%$ (short curing cycle) and $4.4 \%$ (long curing cycle) compared with the control group. The concentration of $5 \%$ silver colloidal nanoparticle showed reduction in the flexural strength by $7.2 \%$ (short curing cycle) and 7.7\% (long curing cycle), which was good.

A few limitations of using silver colloidal nanoparticles were observed during this study. In this study, only flexural strength of acrylic denture base resin modified by different concentrations of silver colloidal nanoparticles was evaluated, still further mechanical properties need to be evaluated, such as impact strength and tensile strength. No in vivo studies have been performed on the silver colloidal nanoparticle incorporation in acrylic denture base resin.

Future perspectives can be the evaluation of other mechanical properties of acrylic resin with different concentrations of silver colloidal nanoparticles and also some in vivo studies related to the silver colloidal nanoparticles.

\section{CONCLUSION}

Within the limitations of this study, following conclusions can be drawn:

- The mean flexural strength value of $0.5 \%$ silver colloidal nanoparticles in denture base resin was above the value of the control group both in short and long curing cycles, whereas the mean flexural strength value of $5 \%$ silver colloidal nanoparticles was below the value of control group both in short and long curing cycles.

- Silver colloidal nanoparticle incorporation at $0.5 \%$ concentration increased the mean flexural strength in both curing cycles by 7.5 and $4.4 \%$, respectively, when compared with the control group, whereas silver colloidal nanoparticle incorporation at $5 \%$ concentration decreased the mean flexural strength in both curing cycles by 7.2 and $7.7 \%$, respectively, when compared with the control group.

Hence, it can be concluded that the specimens incorporated with $0.5 \%$ silver colloidal nanoparticles and processed by long curing cycle showed significant increase in its flexural strength compared with the control group, which makes it clinically suitable 
as a denture base material. However, silver colloidal nanoparticle incorporation at 5\% concentration in PMMA has shown to decrease the flexural strength in both the curing cycles, giving it a questionable prognosis. Further studies are indicated to evaluate the effect of silver colloidal nanoparticle on other mechanical properties of PMMA.

\section{REFERENCES}

1. Al-Dwairi ZN. Prevalence and risk factors associated with denture-related stomatitis in healthy subjects attending a dental teaching hospital in North Jordan. J Ir Dent Assoc 2008 Apr-May;54(2):80-83.

2. Budtz-Jorgensen E, Mojon P, Rentsch A, Deslauriers N. Effects of an oral health program on the occurrence of oral candidiasis in a long term care facility. Community Dent Oral Epidemiol 2000 Apr;28(2):141-149.

3. Braydich-Stolle L, Hussain S, Schlager JJ, Hofmann M-C. In vitro cytotoxicity of nanoparticles in mammalian germline stem cells. Toxicol Sci 2005 Dec;88(2):412-419.

4. Monteiro DR, Gorup LF, Takamiya AS, de Camargo ER, Filho AC, Barbosa DB. Silver distribution and release from an antimicrobial denture base resin containing silver colloidal nanoparticles. J Prosthodont 2012 Jan;21(1):7-15.

5. Rodford RA. Further development and evaluation of high impact strength denture base materials. J Dent 1990;18: 151-157.

6. Vallittu PK, Lessila VP. Reinforcement of acrylic resin denture base material with metal or fibre strengtheners. J Oral Rehabil 1992 May;19(3):385-391.
7. Furno F, Morley KS, Wong B, Sharp BL, Arnold PL, Howdle SM, Bayston R, Brown PD, Winship PD, Reid HJ. Silver nanoparticles and polymeric medical devices: a new approach to prevention of infection? J Antimicrob Chemother 2004 Dec;54(6):1019-1024.

8. American Dental Associated Specification No. 12 for Dental Base Polymers. Chicago: Council on Dental Materials and Devices; 1975.

9. American Dental Associated Specification No. 12 for Denture Base Polymers. Chicago: Council on Dental Materials and Devices; 1999.

10. Jeganathan S, Lin CC. Denture stomatitis-a review of the aetiology, diagnosis and management. Aust Dent J 1992 Apr;37(2):107-114.

11. Kvitek L, Panacek A, Prucek R, Soukupova J, Vanickova M, Kolar M, Zboril R. Antibacterial activity and toxicity of silver-nanosilver versus ionic silver. J Phys Conf Ser 2011;304(1):012029.

12. Chladek G, Mertas A, Barszczewska-Rybarek I, Nalewajek T, Zmudzki J, Król W, Lukaszczyk J. Antifungal activity of denture soft lining material modified by silver nanoparticlesA pilot study. Int J Mol Sci 2011;12(7):4735-4744.

13. Casemiro LA, Martins CH, Pires-de-Souza FC, Panzeri $\mathrm{H}$. Antimicrobial and mechanical properties of acrylic resins with incorporated silver-zinc zeolite-Part I. Gerodontology 2008 Sep;25(3):187-194.

14. Meng TR, Latta MA. Physical properties of four acrylic denture base resins. J Contemp Dent Pract 2005 Nov;6(4):93-100.

15. Arundati R, Patil NP. An investigation into the transverse and impact strength of a new indigenous high-impact denture base resin, DPI-tuff and its comparison with most commonly used two denture base resins. J Indian Prosthodont Soc 2006;6(3):133-138. 